\title{
CLIMA ORGANIZACIONAL: UM ESTUDO NO SETOR CONTÁBIL DO OESTE
}

\author{
CATARINENSE
}

\author{
Cristine Epping ${ }^{1}$ \\ Nathalia Berger Werlang ${ }^{2}$ \\ Camila Hister ${ }^{3}$ \\ Recebido em: 29 out. 2018 \\ Aceito em: 08 maio 2019
}

Como citar este artigo: EPPING, Cristine; WERLANG, Nathalia Berger; HISTER, Camila. CLIMA ORGANIZACIONAL: UM ESTUDO NO SETOR CONTÁBIL DO OESTE CATARINENSE. Revista Visão: Gestão Organizacional, Caçador, SC, Brasil, p. 99-114, jun. 2019. ISSN 2238-9636. Disponível em: <http://dx.doi.org/10.33362/visao.v8i1.1750>.

Resumo: O presente estudo tem como objetivo geral identificar os fatores internos e externos que interferem no clima organizacional dos escritórios de contabilidade do oeste de Santa Catarina. Os procedimentos metodológicos utilizados para a obtenção das respostas basearamse em uma pesquisa quantitativa e descritiva, operacionalizada por aplicação de um questionário de Likert 5 pontos, por meio da técnica survey. A amostra é composta por 66 colaboradores e gestores dos escritórios de contabilidade pertencentes a região de abrangência da Agência de Desenvolvimento Regional de Itapiranga- SC. A pesquisa identificou que o perfil dos entrevistados é formado em maior parte pelo gênero feminino, com idade média de 33 anos, e, em sua maioria, formação superior completo. Resultou-se então, em avaliações positivas em relação aos fatores internos, sendo que em relação ao fator vida profissional, apresentou-se a variável com a maior média e em relação a assistência aos funcionários, mostrou-se a variável com a menor média. Quanto aos fatores externos, a maioria também apresentou médias positivas, em que, a variável que obteve menor média refere-se ao regime político nacional. Finalizando, conclui-se que o clima organizacional dos escritórios de contabilidade da região oeste catarinense, tanto nos fatores internos, quanto externos, pode ser considerado bom, entretanto, alguns pontos ainda precisam ser melhorados, principalmente em relação a assistência aos funcionários, como os seguros de vida, auxílio alimentação e assistência médica e dentária.

Palavras-Chave: Clima organizacional. Fatores internos. Fatores externos. Setor contábil.

ORGANIZATIONAL CLIMATE: A STUDY IN THE ACCOUNTING SECTOR OF WESTERN SANTA CATARINA

Abstract: The present study has as general objective to identify the internal and external

\footnotetext{
${ }^{1}$ Centro Universitário FAI - UCEFF. E-mail: cristty_epping@hotmail.com.

${ }^{2}$ Doutora em Administração na Universidade Federal de Santa Catarina (UFSC). Centro Universitário FAI - UCEFF.

E-mail: nathaliabw@gmail.com.

${ }^{3}$ Centro Universitário FAI - UCEFF. E-mail: histercamila@outlook.com.
} 
factors that interfere in the organizational climate of the accounting offices of the west of Santa Catarina. The methodological procedures used to obtain the answers were based on a quantitative and descriptive research, operationalized by application of a 5 point Likert questionnaire, using the survey technique. The sample is composed of 66 employees and managers of the accounting offices belonging to the region of scope of the Agência de Desenvolvimento Regional de Itapiranga-SC. The research identified that the profile of the interviewees is formed mostly by the female gender, with a mean age of 33 years, and referring to training, the majority have completed higher education. The result was positive evaluations in relation to the internal factors, and in relation to the professional life factor, the variable with the highest average was presented in relation to assistance to the employees, the variable with the lowest average was shown. As for external factors, the majority also presented positive averages, where the variable that obtained lower average refers to the national political regime. Finally, it can be concluded that the organizational climate of accounting offices in the western region of Santa Catarina, both internal and external, can be considered good, however, some points still need to be improved, especially in relation to employee assistance, such as life insurance, food aid and medical and dental assistance.

Keywords: Organizational climate. Internal factors. External factors. Accounting sector.

\section{INTRODUÇÃO}

É possível ressaltar que, o constante desenvolvimento global passou a interferir nas práticas organizacionais, essencialmente, nas relações e comportamentos. Uma vez que, as percepções e estímulos do ambiente afetam o seu clima organizacional, elemento de compreensão necessária para o cotidiano trabalhista, ressaltando o ambiente, sua qualidade de vida e o desempenho dos indivíduos (SIQUEIRA, 2008).

Deste modo, evidencia-se que, segundo Mussak (2010), o clima organizacional exerce influência na motivação, satisfação e comportamento dos colaboradores da organização, pois o desempenho da empresa pode ser melhorado através de um ambiente que atenda às necessidades individuais.

Desta forma, em concordância com Flores (2016), as organizações são caracterizadas como um conjunto humano que, relaciona-se com o ambiente externo para o desenvolvimento da liderança, formulação de estratégias e decisões. Estas, são manifestadas por meio do empenho nas atividades operacionais, nos procedimentos e processos administrativos.

Outrossim, para Araújo et al. (2017), uma peça chave para que as organizações adquirir vantagem competitiva é a criatividade. Fator que, desenvolve o desempenho organizacional por meio de habilidades individuais.

Deste modo, o clima organizacional é calculado pela presença de inúmeras características que, unidas, proporcionam o desempenho criativo nas organizações. Estas, são definidas pelo envolvimento, autonomia, flexibilidade e inovação, liderança, foco no externo e 
integração (ARAÚJO, 2017).

Sob condições enaltecidas, é unânime afirmar que, os indivíduos são peças essenciais na construção do ambiente organizacional e, os gestores empresariais devem estar cientes da importância de prezar pelo desenvolvimento positivo de seus funcionários e corporação.

Diante do exposto, elaborou-se a seguinte questão problema: Quais são os fatores internos e externos que interferem no clima organizacional dos escritórios de contabilidade do extremo oeste de Santa Catarina?

Assim sendo, objetiva-se identificar os fatores internos e externos que interferem no clima organizacional dos escritórios de contabilidade do oeste de Santa Catarina.

Neste contexto, justifica-se a realização do estudo visto que compreender o clima organizacional em escritórios de contabilidade torna-se relevante, uma vez que a contabilidade é um trabalho minucioso, relacionado as áreas tributária, fiscal e trabalhista (CAVALCANTE; NASCIMENTO; CAVALCANTE, 2015).

Para atingir os objetivos do trabalho foi realizada uma pesquisa quantitativa, operacionalizada por meio de uma survey com 66 colaboradores de escritórios de contabilidade da região oeste catarinense.

O artigo está estruturado da seguinte forma: além desta primeira seção de introdução, apresentam-se os principais conceitos teóricos acerca de qualidade de vida organizacional, motivação, satisfação e clima organizacional; a seguir são detalhados os procedimentos metodológicos utilizados na pesquisa; posteriormente são apresentados e discutidos os principais resultados; por fim são apresentadas as considerações finais e as referências bibliográficas da pesquisa.

\section{A QUALIDADE DE VIDA ORGANIZACIONAL PERCEBIDA NA MOTIVAÇÃO DOS FUNCIONÁRIOS}

Evidencia-se que, o trabalho pode ser considerado como um fardo aos indivíduos, ou, uma barreira ao seu desejo de divertir-se. Por outro lado, definições caracterizam que, este pode ser considerado como uma forma de atribuir sentido à vida, considerando o status e o crescimento profissional (RODRIGUES, 2014).

Rodrigues (2014), define ainda que, o trabalho visto como algo indesejado é proveniente da fragmentação, burocratização, normas e riscos, e, como exigências que interferem na vida pessoal e social do indivíduo.

É por meio deste fator que, a compreensão do gestor/empresário é determinante. Visto que, este deve reconhecer a importância de criar condições adequadas ao aprimoramento de seus funcionários, alcançadas através de seu potencial e criatividade (RODRIGUES, 2014). 
Deste modo, a qualidade de vida no trabalho (QVT) é descrita como a vinculação entre os riscos ocupacionais do trabalho, ergonomia, questões de saúde e segurança no trabalho, esforços repetitivos, carga mental, comunicação tecnológica, psicologia do trabalho, significado do trabalho, psicopatologia, processos comportamentais, contrato psicológico de trabalho, expectativas, liderança, motivação, fidelidade, empregabilidade. Todavia, este é considerado de abrangência ampla, e compreende, essencialmente, o bem-estar geral (FRANÇA, 2014).

Segundo Santos e Borges (2018), a qualidade de vida no trabalho é uma forma de elevar o nível de satisfação pessoal dos colaboradores. Deste modo, a relação positiva estabelecida entre o ambiente de trabalho e o estilo de vida, reforça a premissa do trabalho como fator prazeroso.

Outrossim, cientificamente, afirma-se que, a QVT interfere diretamente na satisfação pessoal. Deste modo, é possível apontar que, o ambiente organizacional é influente nas percepções e sentimento dos indivíduos, além de, aprimorar o seu desenvolvimento pessoal (SANTOS E BORGES, 2018).

Bizarria et al. (2018) evidencia que, é necessário estimular a satisfação dos colaboradores através de suas reais motivações, sejam estas espontâneas ou relacionadas a acontecimentos gerais. Este fator, é impulsionador ao desenvolvimento e melhoria contínua.

Santos e Borges (2018) ressaltam ainda que, a relação entre qualidade de vida no trabalho e satisfação pessoal deve ser prezada pelos gestores. Deste modo, cabe as empresas investir em na Gestão de Pessoas, promovendo o bem-estar de seus colaboradores na execução das atividade e crescimento organizacional.

Assim sendo, para a qualidade e satisfação trabalhista, é necessário que, a cultura e o clima organizacional, temas que serão abordados a seguir, desenvolvam-se positivamente no meio empresarial, a fim auxiliar na motivação dos colaboradores.

\section{CULTURA ORGANIZACIONAL}

Segundo Mussak (2010), a cultura organizacional é definida pelos valores da organização que mostram o que é considerado bom ou ruim, servindo como exemplo para o comportamento de seus funcionários e refletindo no desempenho e na relação da organização com o meio.

Outrossim, Gil (2010) afirma que todas as organizações oferecem uma cultura organizacional que se diferencia pelas suas crenças e valores, pela frequência das ações dos membros, pela filosofia que norteia suas políticas e pelo clima expresso na parte física da empresa como também pela interação se seus membros entre si e com o público externo.

Através de sua conceituação, afirma-se que, Russo (2011) ressalta que, a expressão 
cultura organizacional foi estabelecida no final do século XVIII. No entanto apenas as pesquisas feitas a partir da década de 1950 foram realizadas da maneira que a cultura organizacional é vista atualmente.

Ademais, a cultura de uma organização é a forma informal e compartilhada de compreender a vida e a participação organizacional, mantendo os membros unidos e influenciando o seu pensamento em relação ao trabalho. Cita-se que, toda organização possui um sistema de valores e normas fundamentais que molda o comportamento dos colaboradores, auxiliando na compreensão organizacional (WAGNER III; HOLLENBECK, 2012).

À vista disso, diz-se que, a cultura está presente em todos os ambientes, inclusive nas empresas. Os valores, crenças e o modo de vida na empresa são considerados sua cultura organizacional, que, determina o comportamento dos indivíduos. A cultura organizacional é diferente em cada empresa e mantém os membros dela unidos, moldando o comportamento dos colaboradores.

\section{CLIMA ORGANIZACIONAL}

Inicialmente, é possível afirmar que, conforme Pinheiro (2002), fatores relacionados ao clima organizacional, como participação, atividades desafiantes, competição, poder e liberdade, são considerados favoráveis e, as suas presenças no ambiente de trabalho possibilitam a inovação. Por meio da pesquisa de clima organizacional pode-se perceber os fatores que precisam ser melhorados e os fatores acertivos implementados pela empresa, permitindo que, o ambiente de trabalho tonrne-se agradável.

Deste modo, de acordo com Tachizawa, Ferreira e Fortuna (2006) define-se o clima organizacional como a qualidade e influência comportamental instaurada no ambiente institucional. O ambiente interno da organização é influenciado pelo conjunto de crenças e valores que conduzem a relação das pessoas que fazem parte da organização, determinando os pontos favoráveis e desfavoráveis.

Considerado um fenômeno resultante da interação dos elementos culturais, a excessiva importância dada à tecnologia leva a um clima organizacional desumano e, as pressões excessivas dos princípios de autoridade e normativas da organização criam tensões desagradáveis. Já a aceitação dos afetos, sem descuidar os preceitos e o trabalho, promovem um clima organizacional de maior tranquilidade, motivação e confiança. (MATOS; MATOS; ALMEIDA, 2007).

Robbins, Judge e Sobral (2010) conceituam o clima organizacional como a percepção comum que os colaboradores de uma empresa têm em relação a ela e ao seu ambiente de trabalho. Um clima satisfatório no ambiente de trabalho está associado também ao nível de satisfação dos clientes e ao desempenho financeiro da empresa. 
Deste modo, Barthasar (2014) discorre que o clima organizacional é objeto de estudo desde 1927, com o experimento de Hawthorne, foram inauguradas as pesquisas de clima organizacional, tratando-o como um construto que abrange as relações entre colegas, chefia, lideranças, entre outros.

Numericamente, afirma-se que, segundo pesquisa de Wanzeniak e Maciel (2016), os fatores relacionados ao clima organizacional explicam $40,8 \%$ da intenção dos colaboradores permanecerem na empresa. Estes, são definidos pelo comprometimentoo organizacional, salário, volume de trabalho e crescimento profissional.

Araújo et al. (2017), define que, as mudanças relacionadas ao clima organizacional são essenciais para fomentar as habilidades individuais e criativas, refletidas nos valores e aspirações almejados pela organização.

\section{METODOLOGIA DE PESQUISA}

É possível afirmar que, a metodologia é o estudo do método na procura de um determinado conhecimento. Pela etimologia da palavra, método origina do grego methodo, onde meta significa, na direção de, hodo refere-se a caminho (SILVA, 2003).

Deste modo, com o intuito de atender ao objetivo proposto, a pesquisa segue uma abordagem quantitativa por meio do uso do método survey. Rampazzo e Corrêa (2008) afirmam que os princípios que fundamentam a pesquisa quantitativa advêm do positivismo, cujo o puro espírito constitui-se em ver para crer, em estudar o que é, afim de concluir o que será, ou seja, a pesquisa quantitativa apresenta amostragens e destaca com exatidão os dados levantados.

Quanto aos objetivos, a pesquisa caracteriza-se como descritiva. Para Gil (2010) pesquisas descritivas apresentam como objetivo expor características definidas pela população. Ademais, são desenvolvidas para identificar a possível relação entre variáveis.

O instrumento de pesquisa utilizado para a coleta dos dados, constitui-se de uma survey, ou seja, um levantamento de dados em escritórios de contabilidade, por meio da aplicação de um questionário. Gil (2010) determina que as pesquisas, por meio de levantamento, caracterizam-se pela interrogação direta da população cujo comportamento almeja-se conhecer.

A população da pesquisa são todos os funcionários e empregadores dos dezoito escritórios de contabilidade pertencentes aos cinco municípios da região de abrangência da Agência de Desenvolvimento Regional (ADR) de Itapiranga-SC, os quais são: Itapiranga, São João do Oeste, Iporã do Oeste, Tunápolis e Santa Helena.

Por outro lado, sua amostra, conforme Silva (2003), é uma parcela ou porção, convenientemente selecionada da população. A sua percepção não-probabilística, em 
conformidade com Silva (2003), é intencional e possibilita ao pesquisador a escolha de determinado componente da população. E, a amostragem por conveniência é aquela que é escolhida por seus itens serem de maior acessibilidade ou facilidade de avaliação (GRESSLER, 2004).

O estudo está fundamentado em dados primários, isto é, informações não coletadas anteriormente, e também dados secundários, desenvolvidos a partir de pesquisa bibliográfica, estruturada com a leitura de material já preparado por outros autores, constituído por livros e artigos científicos, vantagem perceptível para a investigação de diversos fatores de amplitude que não poderiam ser pesquisados diretamente (GIL, 2010).

De acordo com Rampazzo e Corrêa (2008) o questionário é um conjunto de perguntas elaboradas, com o objetivo de reunir informações sobre as opiniões dos indivíduos a respeito do objetivo da pesquisa. O questionário permite que o pesquisador compreenda um maior número de indivíduos e de informações em espaço de tempo reduzido, comparado com outras técnicas de pesquisa.

Deste modo, o instrumento de coleta de dados primários utilizado é um questionário estruturado de Bispo, que foi elaborado em 2006, e aplicado pessoalmente aos funcionários e empregadores dos escritórios de contabilidade, durante os meses de agosto e setembro, e garantindo aos respondentes o sigilo de todas as informações repassadas.

Para melhor estruturação do questionário, este foi dividido em três blocos, sendo que o primeiro teve como objetivo identificar o perfil dos respondentes, o segundo buscou compreender os fatores internos que influenciam no clima organizacional e o terceiro analisou os fatores externos que influenciam no clima organizacional. O questionário é do tipo Likert 5 pontos (1 - 5), sendo: 1 - Discordo totalmente; 2 - Discordo; 3 - Neutro; 4 - Concordo; 5 Concordo totalmente. Dessa forma, torna-se acessivel a identificação da percepção dos funcionários e empregadores dos escritórios de contabilidade, em relação aos fatores internos e externos que interferem no clima organizacional.

Uma vez que o questionário utilizado para realizar a coleta de dados já é validado, não foi necessário o emprego de um pré-teste. Vale destacar que, apenas algumas expressões foram adaptadas para a realidade desta pesquisa.

Desta forma, os dados foram armazenados no Software Microsoft Excel, e a análise foi realizada por meio do software Statisticals Package for the Social Sciences (SPSS) 22.0, normalmente utilizado em estudos dessas áreas, tornando possível a interpretação da pesquisa. Os dados foram analisados de forma quantitativa, a partir da análise estatística descritiva, com a qual pode-se identificar o perfil dos respondentes e dos escritórios de contabilidade. E as variáveis de percepção dos fatores internos e externos que influenciam no clima organizacional foram analisadas por meio de estatística univariada, com análises de média, desvio padrão, porcentagem e valores mínimos e máximos observados para todas as 
questões.

A apresentação dos resultados foi realizada por meio de tabelas que facilitarão a compreensão das respostas obtidas. Possibilitando a identificação dos fatores internos e externos que interferem no clima organizacional dos escritórios de contabilidade pela visão dos funcionários e gestores.

\section{RESULTADOS}

Esta seção apresentará os resultados do perfil da amostra deste estudo. Em que, todos os respondentes correspondem a média de faixa etária de 33 anos de idade. Esta, varia de 18 a 64 anos, e corresponde a 57,6\% de mulheres e, 42,4\% de homens. Fator que, demostra a importância feminina em escritórios. Destes, 40,9\% são solteiros e 53\% casados. Além de, $6,1 \%$ relatarem que são separados ou divorciados.

Outrossim, é possível destacar que, 37,9\% dos indivíduos consultados possuem ensino superior completo, destes, $25,8 \%$ são pós-graduados. E, 27,3\% possuem ensino médio incompleto. Observa-se que, nestes estabelecimentos da região, o nível de aprendizado não é superior a pós-graduações.

Neste contexto, a rentabilidade de 28,8\% dos respondentes é de 2 a 4 salários mínimos. Outrossim, os que faturam de 4 a 6 salários mínimos correspondem a 22,7\% do englobado.

Deste modo, evidencia-se que, 33,3\% dos estabelecimentos localizam-se na cidade de Itapiranga, seguindo para São João do Oeste, que representa 24,2\% e Iporã do Oeste, com 22, 7\%. Já, Tunápolis e Santa Helena representam, respectivamente, 13,6\% e 6,1\%.

Ressalta-se que, a superioridade do município de Itapiranga ocorre pela quantidade de questionários coletados, visto que, possui o maior número de escritórios e funcionários na região.

\section{ANÁLISE UNIVARIADA DOS CONSTRUTOS}

Por meio de análise univariada dos dados, buscou-se medir o padrão médio da amostra para cada variável do construto. Sendo assim, foram analisadas as estatísticas de média, desvio padrão, valores mínimos e máximos observados.

Para analisar os resultados efetivos, cabe destacar que na mensuração das variáveis, utilizou-se uma escala intervalar Likert de 5 pontos (1-5), sendo: 1 -Discordo totalmente; 2 Discordo; 3 - Neutro; 4 - Concordo; 5 - Concordo totalmente.

O Quadro 1 apresenta a identificação dos fatores internos com as questões. Para facilitar o entendimento, antes de cada questão, é identificada a sigla que representa o fator 
interno de clima organizacional pertencente a pergunta.

Quadro 1- Identificação dos fatores internos com as questões

\begin{tabular}{l|l}
\hline Fatores & Abreviação \\
\hline Vida profissional & VP \\
\hline Estrutura organizacional & EO \\
\hline Incentivos profissionais & IP \\
\hline Remuneração & R \\
\hline Segurança profissional & SP \\
\hline Nível sociocultural & NS \\
\hline Ambiente de trabalho & AT \\
\hline Burocracia & B \\
\hline Cultura organizacional & CO \\
\hline Assistência ao funcionário & AF \\
\hline
\end{tabular}

Fonte: Elaborado pela autora (2016)

A Tabela 1 mostra os resultados das variáveis do construto, que influenciam no ambiente e clima organizacional.

Tabela 1 - Análise de fatores internos que influenciam no clima organizacional

\begin{tabular}{|c|c|c|c|c|}
\hline Afirmações & Média & $\begin{array}{l}\text { Desvio } \\
\text { Padrão }\end{array}$ & Mínimo & Máximo \\
\hline VP1 - Sinto orgulho de trabalhar nesta empresa. & 4,53 & 0,561 & 3 & 5 \\
\hline VP2 - Sinto orgulho da minha atividade nesta empresa. & 4,47 & 0,561 & 3 & 5 \\
\hline $\begin{array}{l}\text { VP3 - Acho que a empresa me oferece um bom plano de } \\
\text { carreira. }\end{array}$ & 4,02 & 0,903 & 1 & 5 \\
\hline $\begin{array}{l}\text { VP4 - Costumo indicar esta empresa como alternativa de } \\
\text { emprego para meus amigos e parentes. }\end{array}$ & 3,86 & 0,802 & 3 & 5 \\
\hline VP5 - Eu me preocupo com o futuro desta empresa. & 4,53 & 0,561 & 3 & 5 \\
\hline $\begin{array}{l}\text { VP6 - Considero que estou obtendo sucesso na minha } \\
\text { carreira e na minha vida profissional. }\end{array}$ & 4,3 & 0,607 & 3 & 5 \\
\hline $\begin{array}{l}\text { VP7 - Gostaria que meus filhos trabalhassem nesta } \\
\text { empresa. }\end{array}$ & 3,8 & 1,026 & 1 & 5 \\
\hline $\begin{array}{l}\text { VP8 - Dependo apenas dos meus próprios esforços para } \\
\text { obter o sucesso profissional e de carreira na empresa. }\end{array}$ & 3,5 & 1,231 & 1 & 5 \\
\hline $\begin{array}{l}\text { VP9 - Os cursos e treinamentos que fiz são suficientes } \\
\text { para o exercício das minhas atividades. }\end{array}$ & 3,45 & 0,995 & 1 & 5 \\
\hline EO1 - Eu confio plenamente no meu chefe imediato. & 4,12 & 0,775 & 2 & 5 \\
\hline EO2 - O meu chefe imediato é um líder. & 4,06 & 0,802 & 2 & 5 \\
\hline $\begin{array}{l}\text { EO3 - O meu chefe imediato é a pessoa mais indicada } \\
\text { para a função que ocupa. }\end{array}$ & 4,17 & 0,714 & 3 & 5 \\
\hline $\begin{array}{l}\text { EO4 - Estou satisfeito com a estrutura hierárquica } \\
\text { (chefes e subordinados) a que estou vinculado. }\end{array}$ & 4,09 & 0,717 & 3 & 5 \\
\hline $\begin{array}{l}\text { IP1- Considero que o meu trabalho é reconhecido e } \\
\text { valorizado pela empresa. }\end{array}$ & 3,98 & 0,813 & 2 & 5 \\
\hline
\end{tabular}




\begin{tabular}{l|l|l|l|l}
\hline $\begin{array}{l}\text { IP2 - Considero que o meu trabalho é reconhecido e } \\
\text { valorizado pela minha família. }\end{array}$ & 4,38 & 0,548 & 3 & 5 \\
\hline $\begin{array}{l}\text { IP3 - Considero que o meu trabalho é reconhecido e } \\
\text { valorizado pelos meus amigos e parentes. }\end{array}$ & 4,26 & 0,563 & 3 & 5 \\
\hline R1 - Acho justo o meu salário atual. & 3,74 & 0,933 & 1 & 5 \\
\hline $\begin{array}{l}\text { R2 - O meu patrimônio é condizente com os esforços } \\
\text { que tenho feito pela empresa. }\end{array}$ & 3,73 & 0,904 & 1 & 5 \\
\hline $\begin{array}{l}\text { SP1 - Meu emprego é seguro na empresa, ou seja, não } \\
\text { corro o risco de ser demitido sem motivo. }\end{array}$ & 3.97 & 0,822 & 2 & 5 \\
\hline $\begin{array}{l}\text { NS1 - O meu nível cultural e intelectual é suficiente para } \\
\text { o exercício das minhas atividades na empresa. }\end{array}$ & 3,92 & 0,664 & 2 & 5 \\
\hline $\begin{array}{l}\text { NS2 - O meu nível social é suficiente para o exercício das } \\
\text { minhas atividades na empresa. }\end{array}$ & 4,06 & 0,630 & 2 & 5 \\
\hline $\begin{array}{l}\text { AT1 - O ambiente de trabalho favorece a execução das } \\
\text { minhas atividades na empresa. }\end{array}$ & 4,26 & 0,590 & 2 & 5 \\
\hline $\begin{array}{l}\text { AT2 - O relacionamento com meus colegas de trabalho } \\
\text { favorece a execução das minhas atividades na empresa. }\end{array}$ & 4,27 & 0,621 & 3 & 5 \\
\hline $\begin{array}{l}\text { B1 - A burocracia adotada na empresa favorece a } \\
\text { execução das minhas atividades na empresa. }\end{array}$ & 3,95 & 0,689 & 1 & 5 \\
\hline $\begin{array}{l}\text { CO1 - As tradições (crenças) da empresa favorecem a } \\
\text { execução das minhas atividades na empresa. }\end{array}$ & 3,83 & 0,670 & 3 & 5 \\
\hline $\begin{array}{l}\text { CO2 - As práticas e costumes adotados na empresa } \\
\text { favorecem a execução das minhas atividades. }\end{array}$ & 4,03 & 0,607 & 3 & 5 \\
\hline $\begin{array}{l}\text { AF1 - A assistência de médico e dentista adotadas na } \\
\text { empresa favorecem a execução das minhas atividades } \\
\text { na empresa. }\end{array}$ & 3,12 & 0,920 & 1 & 5 \\
\hline $\begin{array}{l}\text { AF2 - A assistência para estudantes adotados na } \\
\text { empresa favorecem a execução das minhas atividades } \\
\text { na empresa. }\end{array}$ & 3,74 & 0,771 & 1 & 5 \\
\hline $\begin{array}{l}\text { CHIAVAF3 - A assistência a seguros de vida adotados na } \\
\text { empresa favorecem a execução das minhas atividades } \\
\text { na empresa. }\end{array}$ & 3,00 & 0,911 & 1 & 5 \\
\hline $\begin{array}{l}\text { AF4 - A assistência a alimentação adotados na empresa } \\
\text { favorecem a execução das minhas atividades na } \\
\text { empresa. }\end{array}$ & 3,06 & 0,875 & 1 & 5 \\
\hline Fon & & 5 & 5 \\
\hline
\end{tabular}

Fonte: Dados da pesquisa (2016)

Considerando a Tabela 1, entre as variáveis, os que obtiveram a maior média foram a VP1, sinto orgulho de trabalhar nesta empresa $(4,53)$, mostrando que nestes escritórios de contabilidade os indivíduos orgulham-se do trabalho e desempenham-no eficientemente, e a VP5, que indica eu me preocupo com o futuro desta empresa $(4,53)$, expondo que os funcionários e gestores desses escritórios, buscam o melhor para a empresa e a sua continuidade, esses dois fatores podem estar contribuindo para a motivação e performance dos colaboradores.

Deste modo, percebe-se que, de acordo com a pesquisa realizada por Santos e Borges 
(2018), consequente a relação da qualidade de vida profissional e preocupação com a empresa, aponta-se a satisfação pessoal, que, deve ser prezada, a fim de promover o bem-estar de toda a equipe trabalhista, promovendo a motivação e desenvolvimento coerente e positivo das atividades.

Assim sendo, os gestores, definidores das funções de cada funcionário, devem investir na Gestão de Pessoas, a fim de promovem a satisfação destes colaboradores (SANTOS; BORGES, 2018).

Por outro lado, o quadro 2 apresenta a identificação dos fatores externos com as questões.

Quadro 2 - Identificação dos fatores externos com as questões.

\begin{tabular}{l|l}
\hline Fatores & Abreviação \\
\hline Investimentos e Despesas Familiares & IDF \\
\hline Convivência familiar & CF \\
\hline Situação financeira & SF \\
\hline Vida social & VS \\
\hline Saúde & S \\
\hline Convivência familiar & CFa \\
\hline Time de Futebol & TF \\
\hline Férias e Lazer & FL \\
\hline Segurança pública & SPu \\
\hline Política e Economia & PE \\
\hline
\end{tabular}

Fonte: Elaborado pela autora (2016)

A Tabela 2 apresenta a análise dos fatores externos que influenciam no clima organizacional.

Tabela 2 - Análise de fatores externos que influenciam no clima organizacional

\begin{tabular}{l|l|l|l|l}
\hline Afirmações & Média & $\begin{array}{l}\text { Desvio } \\
\text { Padrão }\end{array}$ & Mínimo & Máximo \\
\hline IDF1 - Eu me preocupo com o futuro da minha família. & 4,88 & 0,329 & 4 & 5 \\
\hline $\begin{array}{l}\text { IDF2 - Estou satisfeito com a alimentação que estou } \\
\text { podendo proporcionar à minha família. }\end{array}$ & 4,18 & 0,802 & 2 & 5 \\
\hline $\begin{array}{l}\text { CF1 - Estou vivendo bem com a minha } \\
\text { esposa/companheira ou o meu marido/companheiro. }\end{array}$ & 4,29 & 0,818 & 3 & 5 \\
\hline CF2 - Estou vivendo bem com os meus filhos. & 3,86 & 1,080 & 1 & 5 \\
\hline SF1 - Estou satisfeito com a minha residência. & 4,27 & 0,833 & 2 & 5 \\
\hline SF2 - Estou satisfeito com o meu carro. & 4,05 & 0,902 & 1 & 5 \\
\hline $\begin{array}{l}\text { SF3 - Estou satisfeito com o vestuário que estou } \\
\text { podendo proporcionar à minha família. }\end{array}$ & 4,15 & 0,728 & 3 & 5 \\
\hline SF4 - Estou com a minha situação financeira em ordem. & 4,12 & 0,713 & 2 & 5 \\
\hline SF5 - Estou satisfeito com o meu patrimônio. & 3,97 & 0,723 & 2 & 5 \\
\hline VS1 - Estou satisfeito com o meu nível social. & 4,14 & 0,605 & 3 & 5 \\
\hline
\end{tabular}




\begin{tabular}{|c|c|c|c|c|}
\hline VS2 - Estou satisfeito com o meu convívio social. & 4,18 & 0,579 & 2 & 5 \\
\hline VS3 - Estou satisfeito com o meu nível intelectual. & 3,88 & 0,734 & 2 & 5 \\
\hline VS4 - Estou satisfeito com o meu nível cultural. & 4,00 & 0,656 & 2 & 5 \\
\hline VS5 - Estou satisfeito com a minha religião. & 3,85 & 0,789 & 2 & 5 \\
\hline S1 - Estou satisfeito com as minhas práticas desportivas. & 3,42 & 0,929 & 1 & 5 \\
\hline S2- Estou satisfeito com o meu estado físico. & 3,56 & 0,806 & 1 & 5 \\
\hline S3 - Estou satisfeito com o meu estado mental. & 4,12 & 0,645 & 2 & 5 \\
\hline CFa1 - Estou satisfeito com a minha vida afetiva. & 4,21 & 0,734 & 2 & 5 \\
\hline CFa2 - Estou satisfeito com a minha vida sexual. & 4,26 & 0,730 & 3 & 5 \\
\hline $\begin{array}{l}\text { TF1 - Estou satisfeito com o time de futebol para o qual } \\
\text { eu torço. }\end{array}$ & 3,33 & 1,100 & 1 & 5 \\
\hline FL1 - Estou satisfeito com as minhas últimas férias. & 3,82 & 0,991 & 1 & 5 \\
\hline $\begin{array}{l}\text { FL2 - Estou planejando para que as minhas próximas } \\
\text { férias sejam muito boas. }\end{array}$ & 4,02 & 0,936 & 1 & 5 \\
\hline $\begin{array}{l}\text { SPu1 - Estou satisfeito com o atual estágio da segurança } \\
\text { pública. }\end{array}$ & 2,76 & 0,993 & 1 & 5 \\
\hline SPu2 - A corrupção altera o meu estado de ânimo. & 3,32 & 1,166 & 1 & 5 \\
\hline SPu3 - A violência altera o meu estado de ânimo. & 3,58 & 0,946 & 1 & 5 \\
\hline SPu4 - A impunidade altera o meu estado de ânimo. & 3,70 & 1,007 & 1 & 5 \\
\hline $\begin{array}{l}\text { PE1 - Estou satisfeito com o atual estágio da política } \\
\text { nacional. }\end{array}$ & 1,74 & 0,771 & 1 & 5 \\
\hline $\begin{array}{l}\text { PE2 - Estou satisfeito com o atual estágio da política } \\
\text { estadual. }\end{array}$ & 2,02 & 0,832 & 1 & 5 \\
\hline $\begin{array}{l}\text { PE3 - Estou satisfeito com o atual estágio da política } \\
\text { municipal. }\end{array}$ & 2,53 & 0,881 & 1 & 4 \\
\hline PE4 - As crises políticas alteram o meu estado de ânimo. & 3,20 & 1,205 & 1 & 5 \\
\hline $\begin{array}{l}\text { PE5 - As crises econômicas alteram o meu estado de } \\
\text { ânimo. }\end{array}$ & 3,42 & 1,082 & 1 & 5 \\
\hline $\begin{array}{l}\text { PE6 - As crises internacionais alteram o meu estado de } \\
\text { ânimo. }\end{array}$ & 2,94 & 1,135 & 1 & 5 \\
\hline
\end{tabular}

Fonte: Dados da pesquisa (2016)

Ponderando a Tabela 2, a variável que obteve a maior média foi a IDF1, eu me preocupo com o futuro da minha família $(4,88)$, está variável foi a única que obteve a resposta mínima 4, e consequentemente o menor desvio padrão da pesquisa, está variável mostra a importância da família e do seu futuro para os respondentes da pesquisa.

As variáveis CF1, estou vivendo bem com a minha esposa/companheira ou o meu marido/companheiro (4,29), SF1, estou satisfeito com a minha residência $(4,27)$, CFa2, estou satisfeito com a minha vida sexual $(4,26)$ e CFa1, estou satisfeito com a minha vida afetiva $(4,21)$, obtiveram as seguintes médias mais altas.

Neste contexto, Santos e Borges (2018) consideram que, a qualidade de vida no trabalho interfere diretamente nas principais preocupações dos colaboradores. Deste modo, 
evidencia-se que, o ambiente de trabalho é fator influente na percepção e desenvolvimento emocional dos indivíduos.

Todavia, nota-se que, o fator que opteve menor colocação é a PE1, estou satisfeito com o atual estágio da política nacional $(1,74)$, apresentando a isatisfação dos funcionários em relação a um ponto externo de extrema importância.

Deste modo, de acordo com França (2014) a qualidade de vida no trabalho é designada por uma abrangência de fatores, que compreendem o bem-estar geral. Assim sendo, ressaltase que, questões políticas interferem na satisfação dos funcionários, uma vez que, as condições definidas e aplicadas politicamente, interferem nas ações empresariais.

\section{CONSIDERAÇÕES FINAIS}

Este estudo, teve como objetivo geral identificar os fatores internos e externos que interferem no clima organizacional dos escritórios de contabilidade do oeste de Santa Catarina e contou com uma amostra de 66 respondentes, funcionários e gestores dos escritórios de contabilidade do oeste catarinense.

Para concretizar a pesquisa, foi realizada uma pesquisa teórico-empírica, descritiva e classifica-se como quantitativa por meio do uso do método survey, pois a pesquisa foi realizada por meio de coleta de dados. A coleta de dados ocorreu por meio de questionários impressos entregues aos funcionários e empregadores dos escritórios de contabilidade.

Quanto ao primeiro objetivo específico que é identificar o perfil dos respondentes da pesquisa, observou-se que a média de idade dos respondentes é de 33 anos, sendo a maioria do gênero feminino e casados, referente a formação a maior parte possui ensino superior completo, alusiva a faixa de renda familiar a maior porcentagem se concentrou na faixa de 2 a 4 salários mínimos. Quanto aos escritórios de contabilidade, a maioria é estabelecido em Itapiranga e possui de 7 a 10 funcionários.

Em relação ao segundo objetivo específico que abordou verificar os fatores que interferem positivamente no clima organizacional dos escritórios, pode-se observar que o fator interno que obteve as questões com a maior média de aprovação foi a vida profissional, sendo elas, sinto orgulho de trabalhar nesta empresa e eu me preocupo com o futuro desta empresa. Isso mostra que os funcionários mantem respeito pela empresa, se orgulham dela e se preocupam com ela.

Alusivo aos fatores externos que influenciam o clima, a questão que obteve a maior média é, eu me preocupo com o futuro da minha família alusiva ao fator, investimentos e despesas familiares, mostrando a importância que os respondentes oferecem aos seus familiares.

Referente ao terceiro objetivo específico, verificar os fatores que interferem 
negativamente no clima organizacional dos escritórios, constatou-se que o fator que obteve a variável com a menor média é a assistência a funcionários com a variável, assistência a seguros de vida adotados na empresa favorecem a execução das minhas atividades na empresa, mostrando que alguns escritórios mantém seguros de vida para os funcionários, mas que em outros, eles não possuem ou a assistência de seguros de vida não é favorável ao cumprimento das atividades dos colaboradores.

Em relação aos fatores externos com a menor média, apontou-se o fator política e economia, várias das questões referentes a este fator obtiveram médias baixas, mostrando que ele interfere muito na motivação dos funcionários e gestores, mas a variável com a menor média foi, estou satisfeito com o atual estágio da política nacional.

Em consonância ao quarto objetivo específico, apontar fatores de melhorias para o clima organizacional nos escritórios, pode-se perceber que os fatores externos não podem ser diretamente alterados pelos escritórios, e referente aos fatores internos, as avaliações foram consideradas bastante positivas em relação a todos os fatores. Porém, algumas melhorias podem ser feitas pelos escritórios para que o clima organizacional fique ainda melhor. Com base na pesquisa, os escritórios apresentam um pouco de deficiência em relação aos benefícios concedidos aos funcionários, de maneira geral.

Todavia, a variável com a menor média foi referente aos seguros de vida oferecidos aos funcionários, e segundo a variável, IDF1, eu me preocupo com o futuro da minha família, que obteve a maior média da pesquisa, os funcionários tem uma preocupação muito grande com o futura da sua família, onde um seguro de vida oferecido pela empresa a ele, estaria proporcionando uma maior estabilidade, no caso de alguma fatalidade. Essa variável pode ser relacionada também aos outros benefícios oferecidos, que também ficaram entre as médias mais baixas dos fatores internos que influenciam no clima, como a assistência médica e de dentista e auxilio alimentação, a implementação ou a melhoria desses benefícios, poderia estar ajudando o funcionário a estar se preocupando menos com alguns fatores externos, ajudandoo a se manter mais motivado no trabalho e a sentir ainda mais orgulho de trabalhar no escritório de contabilidade.

Em relação ao objetivo geral da pesquisa, os resultados mostram que o clima organizacional dos escritórios de contabilidade da região oeste catarinense, tanto nos fatores internos, quanto externos, pode ser considerado bom, sendo que alguns pontos ainda precisam ser trabalhados, para buscar um melhoramento constante no ambiente de trabalho dos mesmos. Finaliza-se em suma que os objetivos pretendidos por este estudo foram alcançados.

\section{REFERÊNCIAS}

ARAÚJO, Cintia Cristina Silva de; MODOLO, Daniela; JUNIOR, Erivaldo Carneiro; VILS, Leonardo. Análise da Relação entre Clima Organizacional e o Desempenho Criativo em 
Organizações Brasileiras. NAVUS - Revista de Gestão e Tecnologia, v. 7, n. 2, p. 97-112, 2017.

BARTHASAR, Margareth T. M. Clima Organizacional: Um Estudo Empírico Com As Guardas Civis Municipais Da Região Do Abc. 2014. 115 f. Dissertação (Mestrado em Administração) Programa de Pós-Graduação em Administração, Universidade Municipal de São Caetano do Sul, São Caetano do Sul, 2014. Disponível em:

<http://www.uscs.edu.br/posstricto/administracao/dissertacoes/2014/pdf/DISSERTACAO_M ARGARETH_TOSCANO\%2OMARTINEZ_BARTHASAR.pdf>. Acesso em: 3026 de out. 2018.

CAVALCANTE, Frederico; NASCIMENTO, Tabata; CAVALCANTE, Maria. Um estudo sobre o clima organizacional em escritórios contábeis do estado do Rio de Janeiro: análise das variáveis do clima. In: IV SINGEP- Simpósio Internacional de Gestão de Projetos, Inovação e Sustentabilidade, 2015. Anais... São Paulo, 2015. Disponível em:

<http://www.singep.org.br/4singep/resultado/81.pdf>. Acesso em: 26 de out. 2018.

FLORES, Rafael Telch. A influência do clima organizacional na empresa e nas pessoas. 2016. Disponível em: <http://www.administradores.com.br/artigos/negocios/a-influencia-do-climaorganizacional-nas-empresas-e-nas-pessoas/98588/>. Acesso em: 17 ago. 2018.

GIL, Antonio C. Como elaborar projetos de pesquisa. 5. ed. São Paulo: Atlas, 2010.

FRANÇA, Ana Cristina. Qualidade de vida no trabalho- QVT: conceitos e práticas nas empresas da sociedade pós-industrial. 2ed. São Paulo: Atlas, 2014.

GRESSLER, Lori A. Introdução à Pesquisa: projetos e relatórios. 2. ed. São Paulo: Layola, 2004. Disponível em:

<https://books.google.com.br/books?id=XHnaj|TNILIC\&pg=PA144\&dq=amostra+por+conveni encia\&hl=pt-BR\&sa=X\&ved=0ahUKEwi_5d-

g6fPMAhXDNSYKHXbWDD8Q6AEIJTAA\#v=onepage\&q\&f=false>. Acesso em: 26 de out. 2018.

MATOS, José G. R.; MATOS, Rosa M. B.; ALMEIDA, Josimar R. Análise do ambiente corporativo: Do caos organizado ao planejamento estratégico das organizações. Rio de Janeiro: E-papers, 2007. Disponível em:

<https://books.google.com.br/books?id=dOjjvV1m7k0C\&pg=PA267\&dq=clima+organizacional $\&$ hl $=$ pt -

BR\&sa=X\&ei=ZRYUVePCKqH7sASAnYHwCA\&ved=0CCoQ6AEwAA\#v=onepage\&q\&f=false>. Acesso em: 26 de out. 2018.

MUSSAK, Eugenio. Gestão humanista de pessoas: o fator humano como diferencial competitivo. Rio de Janeiro: Elsevier, 2010.

RAMPAZZO, Sônia E.; CORRÊA, Fernanda Z. M. Desmitificando a Metodologia Científica: Guia prático para produção de trabalhos acadêmicos. Erechim: Habilis, 2008.

PINHEIRO, Ivan A. Fatores do clima organizacional que são motivadores para a inovação tecnológica em um centro de tecnologia. Revista Eletrônica de Administração, v. 8, n. 5, set/out. 2002. Disponível em: 
<http://www.lume.ufrgs.br/bitstream/handle/10183/19603/000348939.pdf?sequence=1>. Acesso em: 26 de out. 2018.

ROBBINS, Stephen P.; JUGDE, Timothy A.; SOBRAL, Filipe. Comportamento organizacional: Teoria e prática no contexto brasileiro. 14. ed. São Paulo: Pearson Prentice Hall, 2010.

RODRIGUES, Marcus V. Qualidade de Vida no Trabalho: evolução e análise no nível gerencial. 14ed. Petrópolis, RJ: Vozes, 2014.

RUSSO, Giuseppe M. Diagnóstico da Cultura Organizacional: o impacto dos valores organizacionais no desempenho das terceirizações. São Paulo: Dedix, 2011. Disponível em: $<$ https://books.google.com.br/books?id=GqqkKVomr44C\&printsec=frontcover\&dq=diagnostic o+da+cultura+organizacional+ficha+catalografica\&hl=ptBR\&sa=X\&ved=0ahUKEwjr2PTGuKrMAhXB6iYKHXXgCXgQ6AEIKzAA\#v=onepage\&q\&f=false>. Acesso em: 26 de out. 2018.

SANTOS, P. S. D.; BORGES, G. R. A Influência da Satisfação e Qualidade de Vida no Trabalho entre Alunos do Curso de Agronegócio. Revista de Carreiras e Pessoas, v. 8, n. 3, p. 375-397, 2018.

SILVA, Antonio C. R. Metodologia da pesquisa aplicada à contabilidade: orientações de estudos, projetos, artigos, relatórios, monografias, dissertações, teses. São Paulo: Atlas, 2003.

SIQUEIRA, Mirlene Maria Matias. Medidas do comportamento organizacional: ferramentas de diagnóstico e gestão. Porto Alegre: Artmed, 2008.

TACHIZAWA, Takeshy; FERREIRA, Victor; FORTUNA, Antônio. Gestão com pessoas: Uma abordagem aplicada às estratégias de negócios. 5 ed. Rio de Janeiro: Editora FGV, 2006. Disponível em:

<https://books.google.com.br/books?id=y3EOjfSfZNkC\&pg=PA239\&dq=clima+organizacional \&hl=pt-

BR\&sa=X\&ei=KtRXVb3XKNLHsQTGrlHwDQ\&ved=0CC4Q6AEwAQ\#v=onepage\&q=clima\%20org anizacional\&f=false>. Acesso em: 26 de out. 2018.

WAGNER III, John A.; HOLLENBECK, John R. Comportamento Organizacional: Criando vantagem competitiva. São Paulo: Saraiva, 2012.

WANZENIAK, Elisabele D. A.; MACIEL, Alessandra C. A influência dos fatores do clima organizacional da intenção do colaborador permanecer trabalhando na empresa. In: IX Encontro de estudos sobre empreendedorismo e Gestão de pequenas empresas, 2016. Anais... Passo Fundo, 2016. 